Research Article

\title{
Buoyancy Effect on a Micropolar Fluid Flow Past a Vertical Riga Surface Comprising Water-Based SWCNT-MWCNT Hybrid Nanofluid Subject to Partially Slipped and Thermal Stratification: Cattaneo-Christov Model
}

\author{
Ahmed Mohammed Alshehri, ${ }^{1}$ Hasan Huseyin Coban, ${ }^{2}$ Shafiq Ahmad $\left(\mathbb{D},{ }^{3}\right.$ Umair Khan, \\ and Wajdi Mohamad Alghamdi ${ }^{6}$ \\ ${ }^{1}$ Mathematics Department, Faculty of Science, King Abdulaziz University, Jeddah 21521, Saudi Arabia \\ ${ }^{2}$ Department of Electricals and Electronic Engineering, Ardahan University, Muhendislik Fakultesi, Ardahan 75000, Turkey \\ ${ }^{3}$ Department of Mathematics, Quaid-I-Azam University 45320, Islamabad 44000, Pakistan \\ ${ }^{4}$ Department of Mathematical Sciences, Universiti Kebangsaan Malaysia, UKM Bangi, Selangor 43600, Malaysia \\ ${ }^{5}$ Department of Mathematics and Social Sciences, Sukkur IBA University, Sukkur 65200, Sindh, Pakistan \\ ${ }^{6}$ Department of Information Technology, Faculty of Computing and Information Technology, King Abdulaziz University, \\ Jeddah 21589, Saudi Arabia
}

Correspondence should be addressed to Shafiq Ahmad; ashafiq@math.qau.edu.pk

Received 30 December 2020; Revised 7 May 2021; Accepted 8 June 2021; Published 16 June 2021

Academic Editor: Vamsi Krishna

Copyright (c) 2021 Ahmed Mohammed Alshehri et al. This is an open access article distributed under the Creative Commons Attribution License, which permits unrestricted use, distribution, and reproduction in any medium, provided the original work is properly cited.

\begin{abstract}
This paper provides a comprehensive analysis of the mixed convective flow that comprises SWCNT-MWCNT/water hybrid nanofluid containing micropolar fluid through a partially slipped vertical Riga surface. A Cattaneo-Christov heat flux model is used to examine the heat transport rate. The energy equation is gaining more significance with the effect of viscous dissipation and thermal stratification. The flow model is transformed by convenient transformation into nondimensionless form. The numerical results of nonlinear complex equations are collected using the bvp4c built-in function from MATLAB which is based on the finite difference method. The graphical results are obtained for both hybrid nanofluid and simple nanofluid. The temperature distribution for hybrid nanofluid is higher than that for simple nanofluid when the solid volume fraction increases. The axial friction factor increases with solid volume fraction, porosity parameter, and mixed convection parameter. The velocity graph varies inversely with nanofluid volume fraction and micropolar parameter.
\end{abstract}

\section{Introduction}

Because of heat transfer enhancement application, nanofluids are still very interesting to study. Many previous studies have shown that the performance of nanofluid heat transfer is higher than usual fluids. So, it is better to discuss the nanofluid instead of regular fluid. Nanoliquids have a significantly higher thermal conductivity than other liquids, which is one of their most important properties. In industries such as nuclear reactors, transportation, food, electronics, and biomedicine, nanofluids play a significant role. Nanoparticles are very small $(1 \mathrm{~nm}-100 \mathrm{~nm})$ particles that increase the conductivity of normal fluids when applied to them. The shape of nanoparticles is made of metal oxide, carbon tubes (SWCNT and MWCNT), carbide, silicon, and nitride, etc. Choi [1] initially presented nanofluids and used a large range of nanofluids in production processes in the industries. Nadeem et al. [2] evaluated the flow towards a moving wedge with three different nanoparticles and induced magnetic field. Dianchen et al. [3] deliberated the mass and heat transport in the occurrence of carbon nanotubes with the influence of the heat generation 
coefficient. The convection boundary layer that flows across a vertical cone with carbon nanotubes in the existence of magnetohydrodynamics is scrutinized by Rahmat et al. [4]. Shafiq et al. [5] addressed the significance of SWCNTs and MWCNTs through a static wedge under the magnetohydrodynamics (MHD) impact. In the involvement of a uniform magnetic field, Sheikholeslami and Bhatti [6] explored the nanofluid forced convective heat transfer in a porous semiannulus. Saleem et al. [7] numerically investigated the heat transfer enhancement utilizing nanoparticles past a flat surface. Recent studies of nanofluids are scrutinized through attempts [8-20].

Hybrid nanofluids are new nanofluid categories that produced a small particle of metal. Hybrid nanofluids are of remarkable use in modern areas including applied science, engineering, biology, and agriculture. Heat and cooling storage performance can be improved with hybrid nanofluids at a low cost. As a result, nanofluids are more advantageous because they can be used in hybrid fuel turbines, diesel engine oil, and chillers enhancement. MWCNT nanoparticles affect engine oil preparation, as they increase CNT to oil ratios and thermal conductivity. In [21-24], some recent research on hybrid nanoliquid has been noted. Mehryan et al. [25] investigated the effects of the combined convection $\mathrm{Cu}-\mathrm{Al} 2 \mathrm{O} 3 /$ water hybrid nanoliquid and $\mathrm{Al} 2 \mathrm{O} 3$ / water nanoliquid within a square cavity induced by a warm cylinder oscillation. Sundar et al. [26] tested the MWCNTFe2O4/water hybrid nanofluid thermal conductivity within the temperature range of $30^{\circ} \mathrm{C}$ and $60^{\circ} \mathrm{C}$. Baghbanzadeh et al. [27] found out the viscosity and thermal conductivity of the MWCNT/SiO2 hybrid nanofluids. Mackolil and Mahanthesh [28] scrutinized the radiated Casson and nanofluids' flow with numerical computations of exact and statistical under mass and heat flux boundary conditions. Hussain and Muhammad [29] discussed the convective carbon/water flow of wall and hall characteristics in peristaltic with the influence of Soret and Dufour.

Nadeem et al. [30] investigated the interaction of MWNCT and SWNCT across the oscillatory state with the heat transfer. Mahanthesh et al. [31] studied heat transport of hybrid MoS 2-Ag nanoliquid flowing over an isothermal wedge with the importance of viscous dissipation and Joule heating. Temperature and volume concentration on dynamics viscosity of hybrid nanofluids in the presence of ethylene glycol and MWCNT were studied by Afshari et al. [32]. Mackolil and Mahanthesh [33] discussed the analysis of TiO 2-EG nanoliquid in Marangoni convection including temperature-dependent surface tension and nanoparticle aggregation.

Impacts of EMHD (Electro-magnetohydrodynamic) by fluid flows perform an elementary role in the production of momentum and the importance found in thermal reactor, microcoolers, liquid chromatography, and managing the flow in a network of fluidic. According to early research, Gailitis [34] invented the Riga plate flow control method. This system is an electromagnetic actuator, and it retains magnets permanently; a continuous separation of the boundary layer helps decline the pressure drag. Zaib et al. [35] considered the entropy generation effects on the

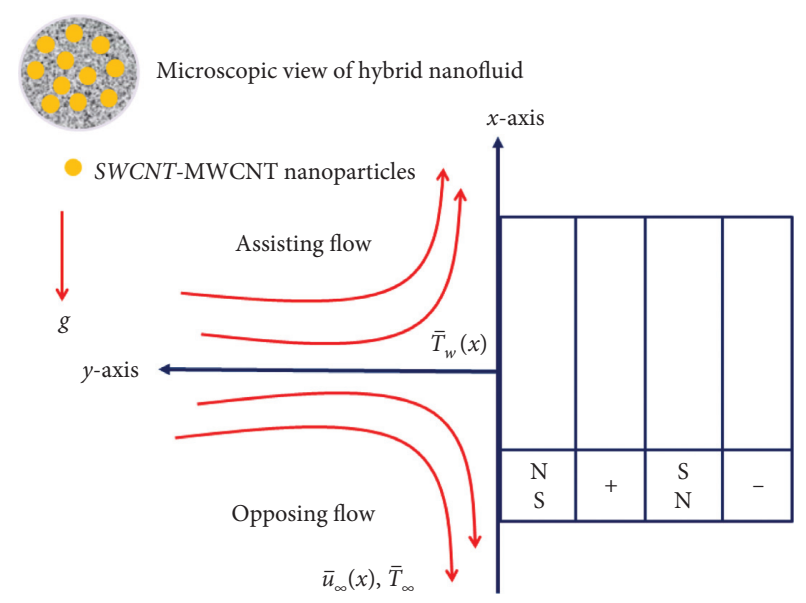

Figure 1: Physical description of the problem.

combined convection micropolar nanofluid flow past a vertical Riga surface. Abbas et al. [36] investigated the entropy production on viscous nanoliquid towards a Riga sheet. Ahmad et al. [37] examined the combined convective flow including nanofluid out of a Riga plate and obtained the analytical solution by a perturbation method. The Riga plate was considered by Magyari and Pantokratoras [38] to examine the influence of Lorentz force on a Blasius electrically conducting fluid flow.

The micropolar liquid is a unique form of non-Newtonian liquid and the most well-known. Liquids with microstructure are called micropolar liquids. Non-Newtonian liquids in our everyday lives include oils, fruit, juice, mud, emulsions, toothpaste, butter, and ointments. Anandha Kumar et al. [39-41] studied the micropolar fluid under different effects. This exploration inspired to examine the influence of mixed convection on the micropolar SWCNTMWCNT|water hybrid nanofluid via a vertical Riga sheet with Cattaneo-Christov heat flux, variable viscosity, viscous dissipation, and thermal stratification. To the best of the reviewer's awareness, no work has been conducted so far on hybrid nanofluids with combined buoyancy effect across a Riga sheet in the existence of micropolar fluid, thermal stratification, and variable viscosity. The transformed equations are explained numerically by applied the MATLAB well-known bvp4c technique. The effect of distinct characteristics on heat and velocity profile is shown graphically and displayed in the table.

\section{Problem Formation}

Consider the two-dimensional micropolar hybrid nanofluid flow with variable viscosity embedded in the porous vertical Riga surface with viscous dissipation. In the existence of thermal stratification and the Cattaneo-Christov heat flux model, the heat equation is further performed. The physical justification of the considered model is explained in Figure 1 where $\bar{v}$ and $\bar{u}$ are velocity components in the directions $y$ and $x$, respectively.

Mathematically, viscosity in the variable form is determined by Shafiq and Nadeem [13]: 


$$
\mu_{f}(\bar{T})=\frac{\mu_{\infty}}{\delta \bar{T}-\delta \bar{T}_{\infty}+1}
$$

Applying the boundary layer approximation, the basic governing equations take place the form as [35, 42, 44, 45]

$$
\begin{aligned}
& \frac{\partial \bar{v}}{\partial y}+\frac{\partial \bar{u}}{\partial x}=0 \\
& \bar{u} \frac{\partial \bar{u}}{\partial x}+\bar{v} \frac{\partial \bar{u}}{\partial y}=\bar{u}_{\infty} \frac{d \bar{u}_{\infty}}{d x}+\frac{1}{\rho_{\mathrm{hnf}}} \frac{\partial}{\partial y}\left(\left(\mu_{\mathrm{hnf}}(\bar{T})+\kappa\right) \frac{\partial \bar{u}}{\partial y}\right)+\frac{(\rho \beta)_{\mathrm{hnf}}}{\rho_{\mathrm{hnf}}} g\left(\bar{T}-\bar{T}_{\infty}\right)+\frac{\pi J_{0} M_{0}}{8 \rho_{\mathrm{hnf}}} e^{(-\pi / d) y} \\
& -\frac{1}{\rho_{\mathrm{hnf}}} \frac{\mu_{\mathrm{hnf}}(\bar{T})}{K^{*}}\left(\bar{u}-\bar{u}_{\infty}\right)+\frac{\kappa}{\rho_{\mathrm{hnf}}} \frac{\partial \bar{N}}{\partial y}, \\
& \bar{v} \frac{\partial \bar{N}_{1}}{\partial y}+\bar{u} \frac{\partial \bar{N}_{1}}{\partial x}=\frac{\gamma_{\mathrm{hnf}}}{j \rho_{\mathrm{hnf}}} \frac{\partial^{2} \bar{N}_{1}}{\partial y^{2}}-\frac{\kappa}{j \rho_{\mathrm{hnf}}}\left(2 \bar{N}_{1}+\frac{\partial \bar{u}}{\partial y}\right) \\
& \frac{\partial \bar{T}}{\partial x} \bar{u}+\frac{\partial \bar{T}}{\partial y} \bar{v}+\lambda_{1}\left(\begin{array}{c}
\bar{u}^{2} \frac{\partial^{2} \bar{T}}{\partial x^{2}}+2 \overline{u v} \frac{\partial^{2} \bar{T}}{\partial x \partial y}+\bar{v}^{2} \frac{\partial^{2} \bar{T}}{\partial y^{2}}+\bar{u} \frac{\partial \bar{v}}{\partial x} \frac{\partial \bar{T}}{\partial y}+\bar{v} \frac{\partial \bar{u}}{\partial y} \frac{\partial \bar{T}}{\partial x} \\
+\bar{v} \frac{\partial \bar{v}}{\partial y} \frac{\partial \bar{T}}{\partial y}+\bar{u} \frac{\partial \bar{u}}{\partial x} \frac{\partial \bar{T}}{\partial x}-\frac{\mu_{\mathrm{hnf}}(\bar{T})}{\left(\rho C_{p}\right)_{\mathrm{hnf}}}\left(2 \bar{u} \frac{\partial \bar{u}}{\partial y} \frac{\partial^{2} \bar{u}}{\partial x \partial y}+2 \bar{v} \frac{\partial \bar{u}}{\partial y} \frac{\partial^{2} \bar{u}}{\partial y^{2}}\right)
\end{array}\right) \\
& =\alpha_{\mathrm{hnf}} \frac{\partial^{2} \bar{T}}{\partial y^{2}}+\frac{\mu_{\mathrm{hnf}}(\bar{T})}{\left(\rho C_{p}\right)_{\mathrm{hnf}}}\left(\frac{\partial \bar{u}}{\partial y}\right)^{2} \text {. }
\end{aligned}
$$

The subjected boundary conditions are

$$
\left\{\begin{array}{l}
\left.\bar{u}\right|_{y=0}=\left.l \mu_{\mathrm{hnf}}(\bar{T}) \frac{\partial \bar{u}}{\partial y}\right|_{y=0}, \\
\left.\bar{v}\right|_{y=0}=0 \\
\left.\bar{T}\right|_{y=0}=\bar{T}_{w}(x)=\bar{T}_{0}+B x, \\
\left.\bar{N}_{1}\right|_{y=0}=-\left.n \frac{\partial \bar{u}}{\partial y}\right|_{y=0} \\
\left.\bar{u}\right|_{y \longrightarrow \infty} \longrightarrow \bar{u}_{\infty}(x) \\
\left.\bar{T}\right|_{y \longrightarrow \infty} \longrightarrow \bar{T}_{\infty}=\bar{T}_{0}+B_{1} x \\
\left.\bar{N}\right|_{y \longrightarrow \infty} \longrightarrow 0
\end{array}\right.
$$

The mathematical symbols in the governing equations are, namely, defined in the nomenclature. From the micropolar model, $n$ is steady with the given closed interval $[0,1]$. The limiting case condition $n=0$ is imposed for the strong concentration where the intense particles near the shrinking/stretching surface do not swivel. The strong concentration and the no-slip condition $N=0$ both are similarly matched at the given limiting case. The microstructure particles have a very small influence near the shrinking surface of the sheet, and this behavior is noted for the condition $n \neq 0$. Particularly in the condition, $n=0.5$ indicates weak concentration. Also, the turbulent boundary layer flows are produced due to the pertinent condition, $n=1$.

Further, the thermal conductivity, variable viscosity, specific heat, and density for SWCNT-MWCNT/water (hybrid nanofluid) and SWCNT/water (nanofluid) are defined as follows [42]:

Simple nanofluid: 


$$
\begin{aligned}
\alpha_{\mathrm{nf}} & =\frac{k_{\mathrm{nf}}}{\left(\rho C_{p}\right)_{\mathrm{nf}}}, \\
\mu_{n f} & =\mu_{f}(1-\phi)^{-2.5}, \\
\left(\rho C_{p}\right)_{\mathrm{nf}} & =\left(\rho C_{p}\right)_{\mathrm{SWCNT}} \phi+\left(\rho C_{p}\right)_{f}(1-\phi), \\
\rho_{\mathrm{nf}} & =\phi \rho_{\mathrm{SWCNT}}+(1-\phi) \rho_{f}, \\
(\rho \beta)_{\mathrm{nf}} & =(\rho \beta)_{\mathrm{SWCNT}} \phi+(\rho \beta)_{f}(1-\phi), \\
\frac{k_{\mathrm{nf}}}{k_{f}} & =\frac{(1-\phi)+2 \phi\left(k_{\mathrm{SWCNT}} / k_{\mathrm{SWCNT}}-k_{f}\right) \ln \left(k_{\mathrm{SWCNT}}+k_{f} / k_{f}\right)}{(1-\phi)+2 \phi\left(k_{f} / k_{\mathrm{SWCNT}}-k_{f}\right) \ln \left(k_{\mathrm{SWCNT}}+k_{f} / k_{f}\right)} .
\end{aligned}
$$

Hybrid nanofluid:

$$
\begin{aligned}
\alpha_{\mathrm{hnf}} & =\frac{k_{\mathrm{hnf}}}{\left(\rho C_{p}\right)_{\mathrm{hnf}}}, \\
\mu_{\mathrm{hnf}} & =\frac{\mu_{f}\left(1-\phi_{1}\right)^{-2.5}\left(1-\phi_{2}\right)^{-2.5}}{1+\theta \theta_{r}}, \\
\left(\rho C_{p}\right)_{\mathrm{hnf}} & =\phi_{2}\left(\rho C_{p}\right)_{\mathrm{SWCNT}}+\left(1-\phi_{2}\right)\left\{\left(1-\phi_{1}\right)\left(\rho C_{p}\right)_{f}+\phi_{1}\left(\rho C_{p}\right)_{\mathrm{MWCNT}}\right\}, \\
\rho_{\mathrm{hnf}} & =\phi_{2} \rho_{\mathrm{SWCNT}}+\left(1-\phi_{2}\right)\left\{\left(1-\phi_{1}\right) \rho_{f}+\phi_{1} \rho_{\mathrm{MWCNT}}\right\}, \\
(\rho \beta)_{\mathrm{hnf}} & =(\rho \beta)_{\mathrm{SWCNT}} \phi_{2}+\left(1-\phi_{2}\right)\left\{\left(1-\phi_{1}\right)(\rho \beta)_{f}+\phi_{1}(\rho \beta)_{\mathrm{MWCNT}}\right\}, \\
\frac{k_{\mathrm{hnf}}}{k_{b f}} & =\frac{\left(1-\phi_{2}\right)+2 \phi_{2}\left(k_{\mathrm{SWCNT}} / k_{\mathrm{SWCNT}}-k_{b f}\right) \ln \left(k_{\mathrm{SWCNT}}+k_{b f} / k_{b f}\right)}{\left(1-\phi_{2}\right)+2 \phi_{2}\left(k_{b f} / k_{\mathrm{SWCNT}}-k_{f}\right) \ln \left(k_{\mathrm{SWCNT}}+k_{f} / k_{f}\right)},
\end{aligned}
$$

where

$$
\frac{k_{\mathrm{bf}}}{k_{f}}=\frac{\left(1-\phi_{1}\right)+2 \phi_{1}\left(k_{\mathrm{MWCNT}} / k_{\mathrm{MWCNT}}-k_{f}\right) \ln \left(k_{\mathrm{MWCNT}}+k_{f} / k_{f}\right)}{\left(1-\phi_{1}\right)+2 \phi_{1}\left(k_{f} / k_{\mathrm{MWCNT}}-k_{f}\right) \ln \left(k_{\mathrm{MWCNT}}+k_{f} / k_{f}\right)} \text {. }
$$

Here the solid volume fraction of MWCNT and SWCNT are, respectively, exemplified by $\phi_{1}$, and $\phi_{2}$ and $k_{f}$ identify the water-based thermal conductivity of the fluid; specific heat is symbolized by $C_{p}$. The deviation amount for thermophysical properties applied in this examination is categorized in Table 1. 
TABLE 1: Thermo-physical properties of water and CNTs (SWCNT and MWCNT) [42].

\begin{tabular}{lccc}
\hline Physical characteristics & Water & MWCNTs & SWCNTs \\
\hline$C_{p}\left(\mathrm{~J} \mathrm{~kg}^{-1} \mathrm{~K}^{-1}\right)$ & 4179 & 796.00 & 425.00 \\
$\rho\left(\mathrm{kg} \mathrm{m}^{-3}\right)$ & 997.1 & 16.00 & 2600.00 \\
$K\left(\mathrm{~W} \mathrm{~m}^{-1} \mathrm{~K}^{-1}\right)$ & 0.613 & 3000.00 & 6600.00 \\
$\operatorname{Pr}$ & 6.2 & - & - \\
\hline
\end{tabular}

2.1. Similarity Transformation Conversion. The following similarity transformation is used [42]:

$$
\begin{aligned}
\eta & =\sqrt{\frac{c}{v_{f}}} y, \\
\theta(\eta) & =\frac{\bar{T}-\bar{T}_{\infty}}{\bar{T}_{w}-\bar{T}_{0}}, \\
\bar{N}_{1} & =c x \sqrt{\frac{c}{v_{f}}} g(\eta), \\
\bar{u} & =c x f^{\prime}(\eta), \\
\bar{v} & =-\sqrt{c v_{f}} f(\eta),
\end{aligned}
$$

where $v_{f}$ represents the kinematic viscosity of the carrierbased liquid.

Applying equation (10), equations (2)-(6) transmuted to the following dimensional form of ODEs as follows:

$$
\begin{aligned}
\left(\frac{1}{A_{2}\left(1+\theta_{r} \theta\right)}+K\right) f^{\prime \prime \prime} & +H a e^{-\Lambda \eta}+A_{1}\left(f f^{\prime \prime}+1-f^{\prime 2}\right) \\
& -\frac{\theta_{r} \theta^{\prime} f^{\prime \prime}}{A_{2}\left(1+\theta_{r} \theta\right)^{2}}+\mathrm{Kg}^{\prime} \\
& -\frac{P_{m}}{\left(1+\theta_{r} \theta\right) A_{2}}\left(f^{\prime}-1\right)+\lambda A_{4} \theta=0,
\end{aligned}
$$

$$
\left(\frac{\left(1+\theta_{r} \theta\right)^{-1}}{A_{2}}+\frac{K}{2}\right) g^{\prime \prime}-K 2 g+K f^{\prime \prime}-A_{1}\left(f^{\prime} g-f g^{\prime}\right)=0
$$

$$
\begin{aligned}
A_{6} \theta^{\prime \prime} & +\operatorname{Pr} A_{5}\left[f \theta^{\prime}-f^{\prime} \theta-S_{1} f^{\prime}-\gamma\left\{\theta f^{\prime 2}+S_{1} f^{\prime 2}-f f^{\prime \prime} \theta^{\prime}\right.\right. \\
& \left.\left.-S_{1} f f^{\prime \prime}-f f^{\prime} \theta^{\prime}+f^{2} \theta^{\prime \prime}\right\}\right] \\
+ & \frac{E_{c} \operatorname{Pr} f^{\prime \prime 2}}{\left(1+\theta \theta_{r}\right) A_{2}}-\frac{2 \gamma E_{c} \operatorname{Pr}}{\left(1+\theta \theta_{r}\right) A_{2}}\left(f^{\prime \prime \prime} f f^{\prime \prime}-f^{\prime \prime 2} f^{\prime}\right)=0,
\end{aligned}
$$

while the transform appropriate conditions are

$$
\left\{\begin{array}{l}
f^{\prime}(0)=\frac{s f^{\prime \prime}(0)}{A_{2}\left(1+\theta \theta_{r}\right)}, g(0)=-n f^{\prime \prime}(0), f(0)=0, \text { and } \theta(0)=1-S_{1}, \\
f^{\prime}(\eta)=1, \theta(\eta)=0 \text { and } g(\eta)=0, \quad \text { at } \eta \longrightarrow \infty .
\end{array}\right.
$$

The dimensionless parameter involved in equations 11)-(14) is identified as follows:

$$
\begin{aligned}
& A_{1}=\left(\left(1-\phi_{2}\right)\left\{\left(1-\phi_{1}\right)+\phi_{1} \frac{\rho_{\mathrm{MWCNT}}}{\rho_{f}}\right\}+\phi_{2} \frac{\rho_{\mathrm{SWCNT}}}{\rho_{f}}\right), \\
& \Lambda=\frac{\pi \sqrt{v_{f}}}{d \sqrt{c}} \\
& \gamma=c \lambda_{1}, \\
& H a=\frac{\pi J_{0} M_{0}}{8 c^{(3 / 2)} \operatorname{Re}_{x}^{(1 / 2)} \rho_{f} \sqrt{v_{f}}}, \\
& A_{4}=\frac{\rho_{\mathrm{SWCNT}}}{\rho_{f}} \frac{\beta_{\mathrm{SWCNT}}}{\beta_{f}} \phi_{2} \\
& +\left(1-\phi_{2}\right)\left\{1-\phi_{1}+\phi_{1} \frac{\rho_{\mathrm{MWCNT}}}{\rho_{f}} \frac{\beta_{\mathrm{MWCNT}}}{\beta_{f}}\right\}, \\
& \theta_{r}=\delta\left(\bar{T}_{w}-\bar{T}_{\infty}\right), \\
& A_{2}=\left(1-\phi_{1}\right)^{2.5}\left(1-\phi_{2}\right)^{2.5} \text {, } \\
& A_{3}=\left(\left(1-\phi_{2}\right)\left\{\left(1-\phi_{1}\right)+\phi_{1} \frac{\left(\rho C_{p}\right)_{\mathrm{MWCNT}}}{\left(\rho C_{p}\right)_{f}}\right\}\right. \\
& \left.+\phi_{2} \frac{\left(\rho C_{p}\right)_{\mathrm{SWCNT}}}{\left(\rho C_{p}\right)_{f}}\right) \text {, } \\
& j=\frac{v_{f}}{c}, \\
& A_{6}=\frac{k_{h n f}}{k_{f}}, \\
& P_{m}=\frac{v_{f}}{c K^{*}}, \\
& K=\frac{\kappa}{\mu_{f}}, \\
& A_{5}=\left(\left(1-\phi_{2}\right)\left\{\left(1-\phi_{1}\right)+\phi_{1} \frac{\left(\rho C_{p}\right)_{\mathrm{MWCNT}}}{\left(\rho C_{p}\right)_{f}}\right\}\right. \\
& \left.+\phi_{2} \frac{\left(\rho C_{p}\right)_{\mathrm{SWCNT}}}{\left(\rho C_{p}\right)_{f}}\right) \\
& \lambda=\frac{g \beta_{f} b}{c^{2}}=\frac{G r_{x}}{\operatorname{Re}_{x}^{2}} \\
& \operatorname{Pr}=\frac{\nu_{f}}{\alpha_{f}}, \\
& s=l \mu_{f} \sqrt{\frac{c}{v_{f}}} .
\end{aligned}
$$


2.2. Engineering Physical Quantities of Interest. The local skin friction is stated as

$$
C_{f}=\frac{\tau_{w}}{\rho_{f} \bar{u}_{\infty}^{2}},
$$

where $\tau_{w}=\left.\left(\left(\kappa+\mu_{h n f}(\bar{T})\right)(\partial \bar{u} / \partial y)+\kappa \bar{N}_{1}\right)\right|_{y=0}$ is the wall shear stress for the micropolar hybrid nanofluid. Using (10) into equation (16), the following reduced dimensionless form of the skin friction takes place as

$$
\operatorname{Re}_{x}^{(1 / 2)} C_{f x}=\frac{1}{A_{1}}\left[K(1-n)+\frac{1\left(1+\theta_{r} \theta(0)\right)}{A_{2}}\right] f^{\prime \prime}(0),
$$

whereas the local Reynolds number is indicated as $R e_{x}=\left(x \bar{u}_{\infty} / \nu_{f}\right)$.

\section{Methodology of the Numerical Solution}

The system of equations (11)-(13) is obtained in the form of dimensionless ODEs along with appropriate boundary stipulations (14), after using self-similarity transformations (10). The systems of equations are highly nonlinear and difficult to solve exactly. Therefore, the solution to the current investigation is achieved numerically by the MATLAB bvp4c technique. It is a built-in function from MATLAB and is based on the finite difference scheme which is generally known as Lobatto IIIA formula. This method is working only when the dimensionless ODEs are in the firstorder ODEs. For the working process of the considered method, we need to transform our equations from the higher third and second order into a first order by implementing the new variables. Let the new variables are as follows:

$$
\begin{aligned}
& f=y_{1}, \\
& f^{\prime}=y_{2} \text {, } \\
& f^{\prime \prime}=y_{3} \text {, } \\
& y y 1=\left(\frac{1}{\left(1+\theta_{r} \theta\right) A_{2}}+K\right)^{-1}\left\{\begin{array}{c}
-A_{1}\left(1+y_{1} y_{3}-y_{2}^{2}\right)+\frac{\theta_{r} y_{7} y_{3}}{A_{2}\left(1+\theta_{r} \theta\right)^{2}}-\frac{P_{m}}{A_{2}\left(1+\theta_{r} \theta\right)}\left(1-y_{2}\right) \\
-H a e^{-\Lambda \eta}-K y_{5}-\lambda A_{4} A_{2} \theta
\end{array}\right\}, \\
& g=y_{4}, \\
& g^{\prime}=y_{5} \text {, } \\
& y y_{2}=\left(\frac{1}{A_{2}\left(1+\theta_{r} \theta\right)}+\frac{K}{2}\right)^{-1}\left\{A_{1}\left(y_{2} y_{4}-y_{1} y_{5}\right)+K\left(2 y_{4}+y_{3}\right)\right\}, \\
& \theta=y_{6}, \\
& \theta^{\prime}=y_{7}, \\
& y y 3=\frac{-1}{\left(A_{6}-\gamma \operatorname{Pr} A_{5} y_{1}^{2}\right)}\left\{\begin{array}{c}
\frac{E_{c} \operatorname{Pr} y_{3}^{2}}{\left(1+y_{6} \theta_{r}\right) A_{2}}+\operatorname{Pr} A_{5}\left[y_{1} y_{7}-y_{2} y_{6}-y_{2} S_{1}-\gamma\left\{\begin{array}{c}
S_{1} y_{2}^{2}+y_{2}^{2} y_{6} \\
-S_{1} y_{1} y_{3}-y_{1} y_{3} y_{7} \\
-y_{1} y_{2} y_{7}
\end{array}\right\}\right], \\
+\frac{2 \gamma E_{c} \operatorname{Pr}}{\left(1+y_{4} \theta_{r}\right) A_{2}}\left(y_{2} y_{3}^{2}-y_{1} y_{3} y y 1\right)
\end{array}\right\}
\end{aligned}
$$

with the transform initial conditions 


$$
\begin{aligned}
y_{0}(2)-\frac{s}{A_{2}\left(1+\theta \theta_{r}\right)} y_{0}(3) & =0, \\
y_{0}(1) & =0, \\
y_{0}(4)+n y_{0}(3) & =0, \\
y_{0}(6)-1+S_{1} & =0, \\
y_{\text {inf }}(2)-1 & =0, \\
y_{\text {inf }}(4) & =0, \\
y_{\text {inf }}(6) & =0 .
\end{aligned}
$$

To solve the aforementioned equations, the system required initial early guesses at the mesh point to accomplish our conditions (24). For clearer and better understanding of the current method bvp4c, the detail flow chart has also been added (see Figure 2). A convergence criterion $10^{-8}$ is provided for the solution which has been obtained. We have set appropriate finite values $\eta \longrightarrow \infty$, that is, $\eta=\eta_{\infty}=2.5$ to 4 , based on the values of the suggested variables.

\section{Results and Discussion}

This section of the work demonstrates the consequences of the involved sundry parameter in the considered problems on velocity profiles, microrotation profiles, temperature profiles, and shear stress. The impacts of these parameters are shown through various different graphs (see Figures 3-18). For the computation purposes, we have fixed the value of the constraint throughout the simulation as the following $\operatorname{Pr}=6.2, s=0.7, n=0.5, \Lambda=0.5$, $\gamma=0.3, \quad H a=0.1, \quad \theta_{r}=1.0, \quad \lambda=-1.1, \quad P_{m}=0.7, \quad$ and $K=0.25$. The visual findings are addressed for both SWCNT-MWCNT/water hybrid nanofluid and SWCNT/ water nanofluid. The current issue demonstrates strong alignment with the recently published article that is explained in Table 2.

4.1. The Behavior of Different Characteristics on the Velocity Field. The impact on velocity distribution of the $s$ (slip parameter), $\mathrm{Ha}$ (modified Hartman number), $P_{m}$ (porosity parameter), $\theta_{r}$ (variable viscosity parameter), $\phi_{2}$ (solid volume fraction), and $K$ (micropolar parameter) is depicted in Figures $3-8$. Figure 3 is considered to capture the influence of $s$ on velocity $f^{\prime}(\eta)$. On velocity distribution, it displays rising behavior. On both nanofluid and hybrid nanofluid, the thickness of the velocity boundary layer is often observed to be decreasing. Figure 4 explains that as $\mathrm{Ha}$ increased, the velocity field increases. Physically, the $\mathrm{Ha}$ values result in the enhancement of internal and external forces including electric forces and adhesive. In these forces, the momentum flow increases, as an effective fluid velocity rises. The influence of $P_{m}$ on $f^{\prime}(\eta)$ is sketched in Figure 5. With the increasing estimate, $P_{m}$, the thickness of the momentum boundary layer declines. Figure 6 highlights that

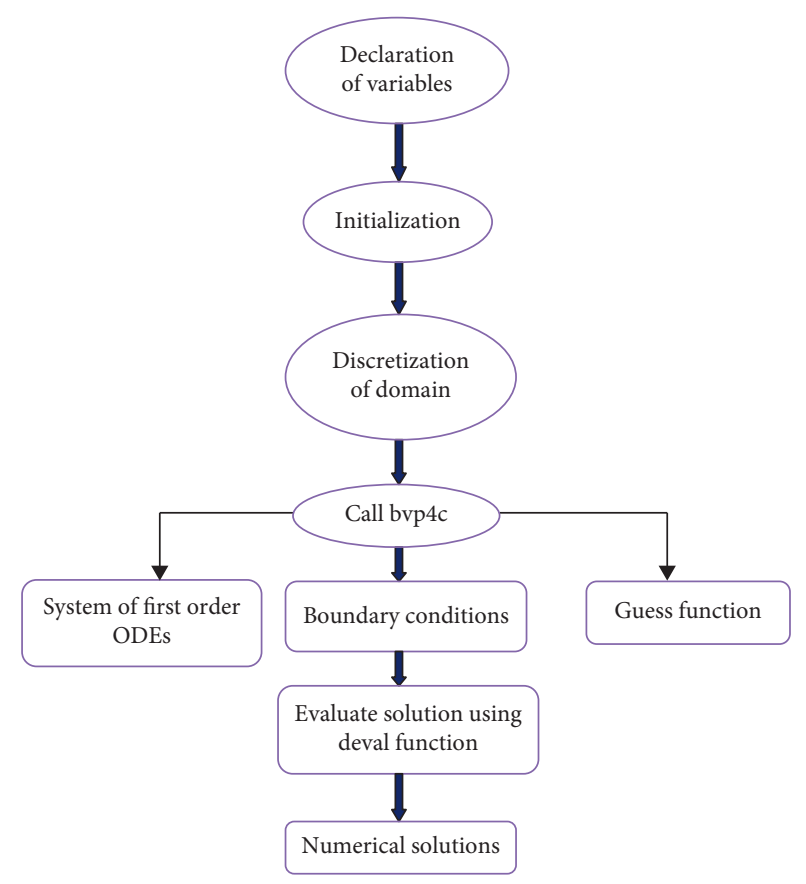

FIGURE 2: Flow chart of the considered numerical solution.

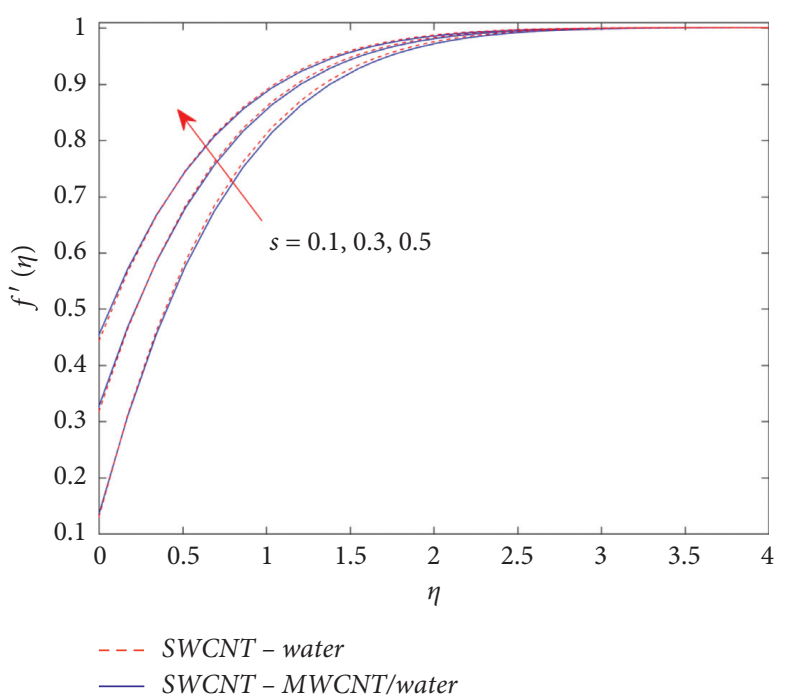

Figure 3: Influence of $s$ on $f^{\prime}(\eta)$.

TABLE 2: Variation of the skin friction coefficient previously published papers when $\lambda=1$ and $P_{m}=K=\theta_{r}=\phi_{i}=0$.

\begin{tabular}{lccc}
\hline $\operatorname{Pr}$ & Aman et al. [43] & $\begin{array}{c}\operatorname{Re}_{x}^{(1 / 2)} C_{f x} \\
\text { Zaib et al. [35] }\end{array}$ & Present result \\
\hline 0.7 & 1.7063 & 1.7063 & 1.7064 \\
1.0 & 1.6754 & 1.6754 & 1.6753 \\
7.0 & 1.5179 & 1.5179 & 1.5180 \\
10 & 1.4928 & 1.4928 & 1.4928 \\
20 & 1.4485 & 1.4485 & 1.4486 \\
40 & 1.4101 & 1.4101 & 1.4102 \\
50 & 1.3989 & 1.3989 & 1.3989 \\
60 & 1.3903 & 1.3903 & 1.3903 \\
80 & 1.3773 & 1.3776 & 1.3773 \\
\hline
\end{tabular}




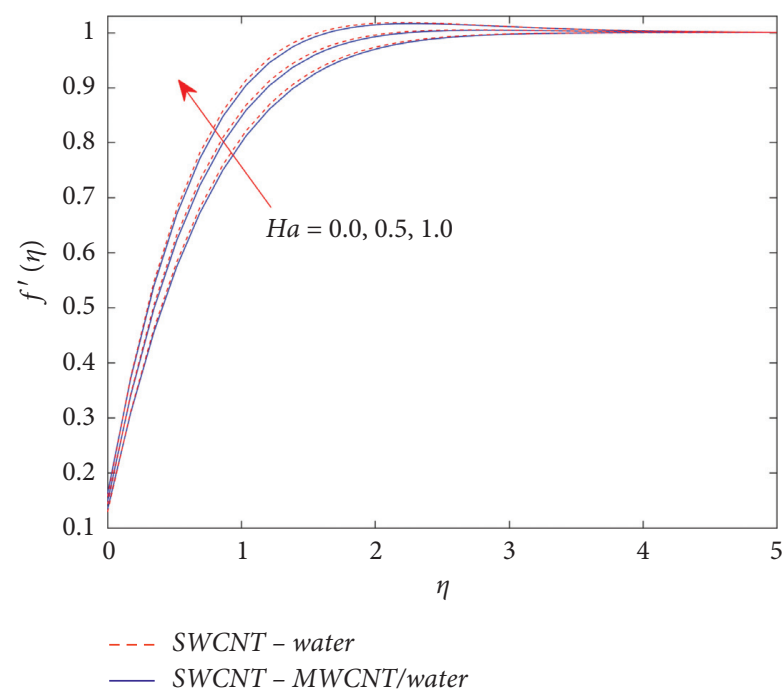

Figure 4: Effect of $\mathrm{Ha}$ on $f^{\prime}(\eta)$.

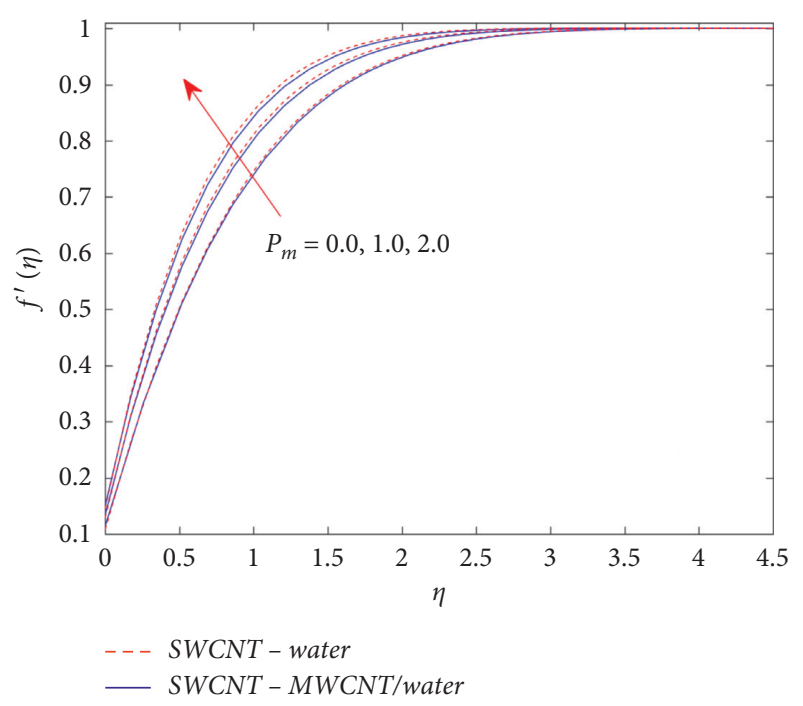

Figure 5: Upshot of $P_{m}$ on $f^{\prime}(\eta)$.

$f^{\prime}(\eta)$ is affected by variation in $\theta_{r}$. Physically, due to the addition in $\theta_{r}$, momentum transfer exists by the small fluid viscosity which boosts the velocity. Figure 7 analyzes that the velocity field decreases as we increase the solid volume fraction. It is because of the larger thermal conductivity of CNTs with higher $\phi_{2}$ which declines the fluid velocity. The velocity of fluid diminishes with the increase of $K$, while its corresponding momentum boundary layer thickness improves (see in Figure 8).

\subsection{Impact of Different Characteristics on Microrotation} Profiles. The characteristic of the micropolar parameter $K$ on the microrotation field is exhibited in Figure 9. It is visible from the observation of certain figure that $g(\eta)$ is reduced by growing $K$. It is further observed that near the surface, the

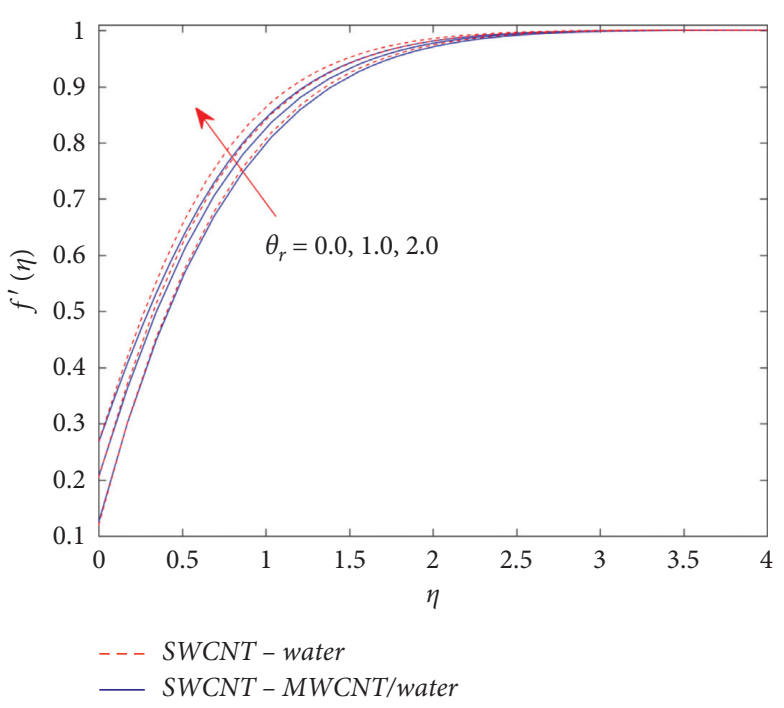

Figure 6: Effect of $\theta_{r}$ on $f^{\prime}(\eta)$.

microrotation profile enhances for both simple and hybrid nanofluids. Figures 10 and 11 are designed to see the variance of the microrotation field for various parameters of flow, including solid volume fraction $\phi_{2}$ and variable vis$\operatorname{cosity} \theta_{r}$. It is seen from these figures that the microrotation profile $g(\eta)$ enhances both $\phi_{2}$ and $\theta_{r}$.

4.3. Effect of Various Parameters on Fluid Temperature. Figures 12-16 justify that how $\gamma$ (thermal relaxation time), $\phi_{2}$ (solid volume fraction), $E_{c}$ (Eckert number), $S_{1}$ (thermal stratification parameter), and $\lambda$ (mixed convection parameter) affect $\theta(\eta) . \theta(\eta)$ is plotted in Figure 12 as $\phi_{2}$ varies. Due to an increase in the solid volume fraction, the conductivity of thermal enhances which improves the temperature $\theta(\eta)$. In Figure 13, $\theta(\eta)$ reduces with improving values of $\gamma$. Physically, it is because particles express a nonconductive attitude as we escalate $\gamma$, i.e., it takes longer for particles to disperse heat to their neighboring particles, which is responsible for lowering the distribution of temperature. Figure 14 confirms that $\theta(\eta)$ decreases with $\lambda . \theta(\eta)$ improves with improving $E_{c}$ (see in Figure 15). The mechanical fluid's energy is converted to thermal energy for an increase of the Eckert number $\left(E_{c}\right)$ from 0 to 1 due to internal molecular friction. As seen from Figure 16, $\theta(\eta)$ reduces $S_{1}$. Physically, change $S_{1}$ decreases the difference in temperature between the surface and ambient fluid that contributes to the smaller temperature.

4.4. Effect of Several Parameters on Skin Friction. Figures 17 and 18 illustrate the skin friction $R e_{x}^{1 / 2} C_{f x}$ against $\phi_{2}$ (solid volume fraction) with the impact of $\lambda$ and $P_{m}$. Figure 17 scrutinized the increasing behavior when $\lambda$ and $\phi_{2}$ boost. Figure 18 demonstrated the impact of solid volume fraction and porosity parameter on $R e_{x}^{(1 / 2)} C_{f x}$. From the figure, it is explained that, for both values of $P_{m}$ and $\phi_{2}$, $\operatorname{Re}_{x}^{1 / 2} C_{f x}$ boosts. 

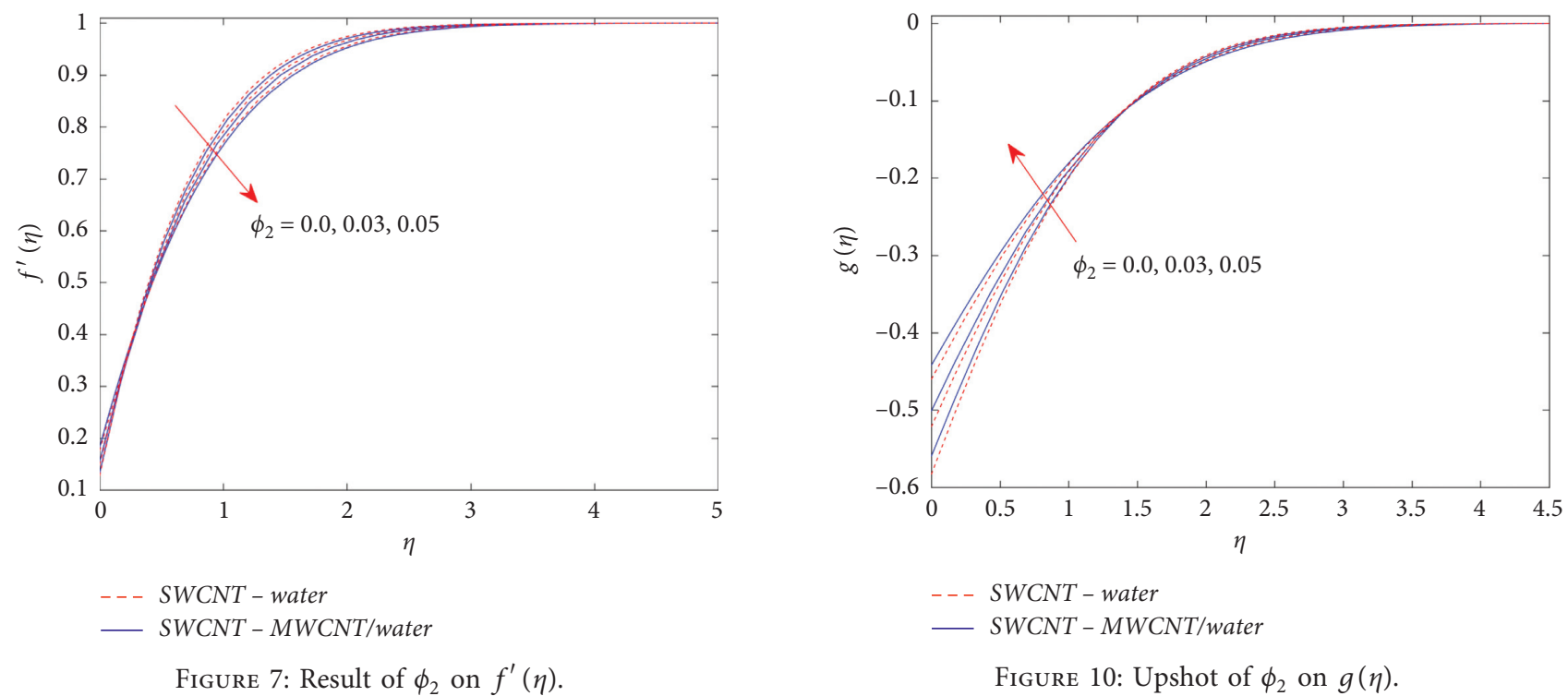

FIgURE 7: Result of $\phi_{2}$ on $f^{\prime}(\eta)$.

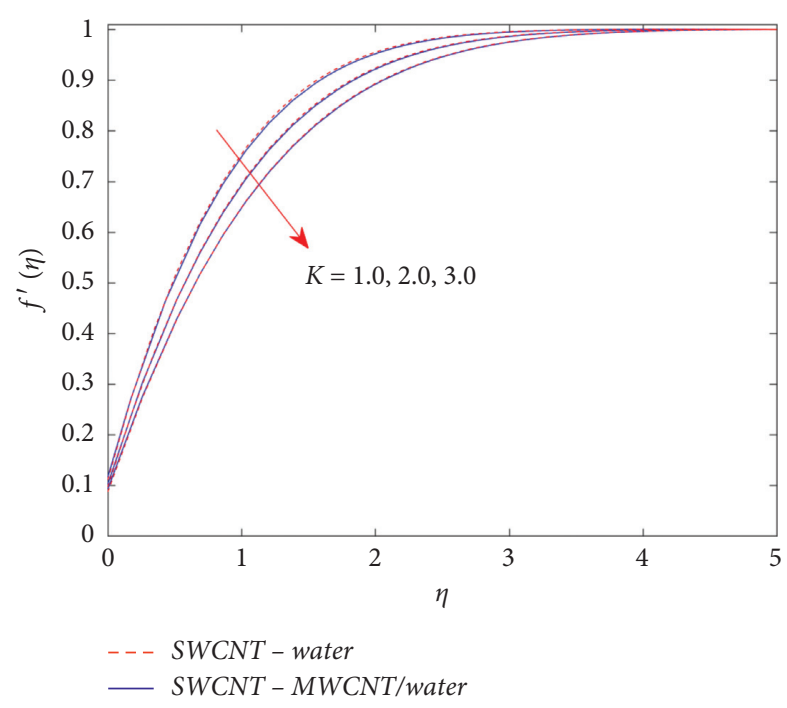

Figure 8: Influence of $K$ on $f^{\prime}(\eta)$.
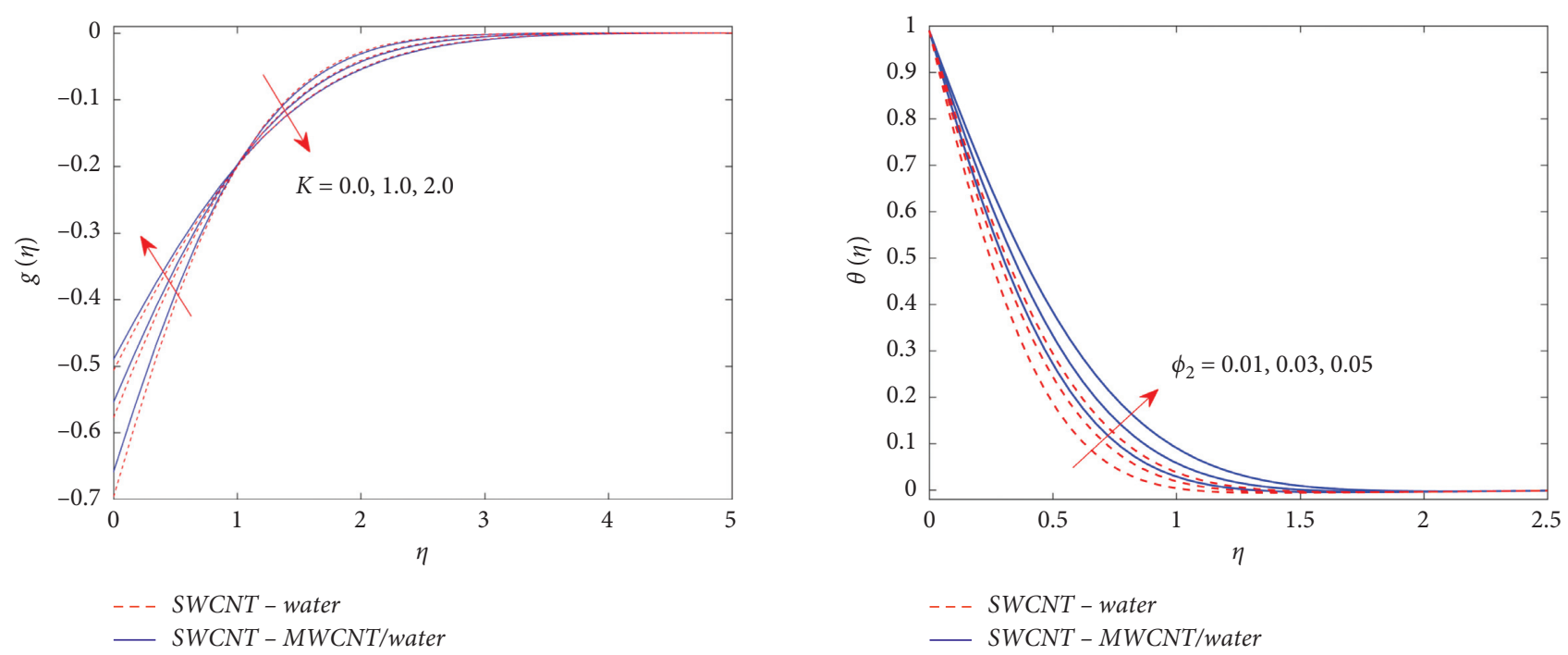

Figure 9: Impression of $K$ on $g(\eta)$.

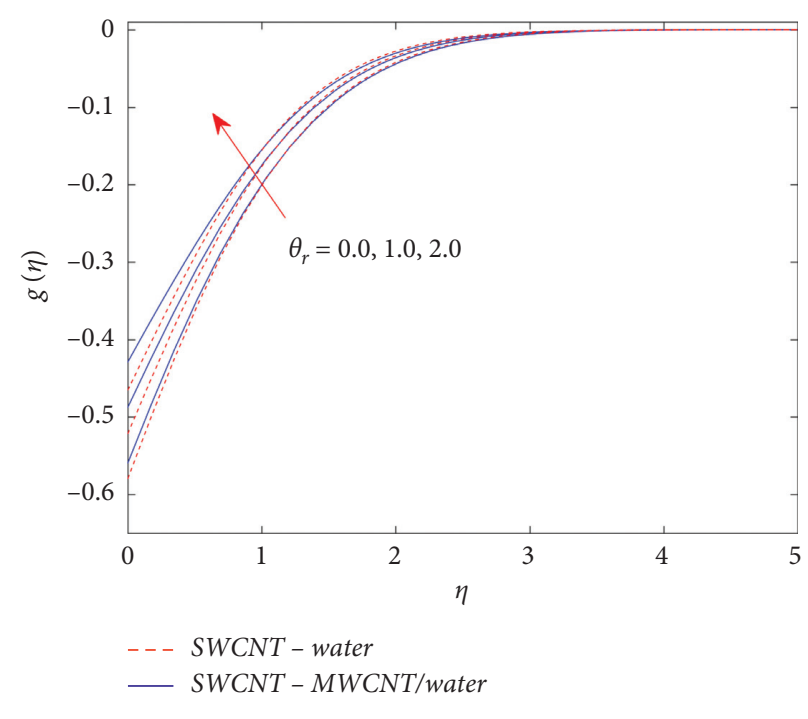

Figure 11: Result of $\theta_{r}$ on $g(\eta)$.

Figure 12: Impact of $\phi_{2}$ on $\theta(\eta)$. 


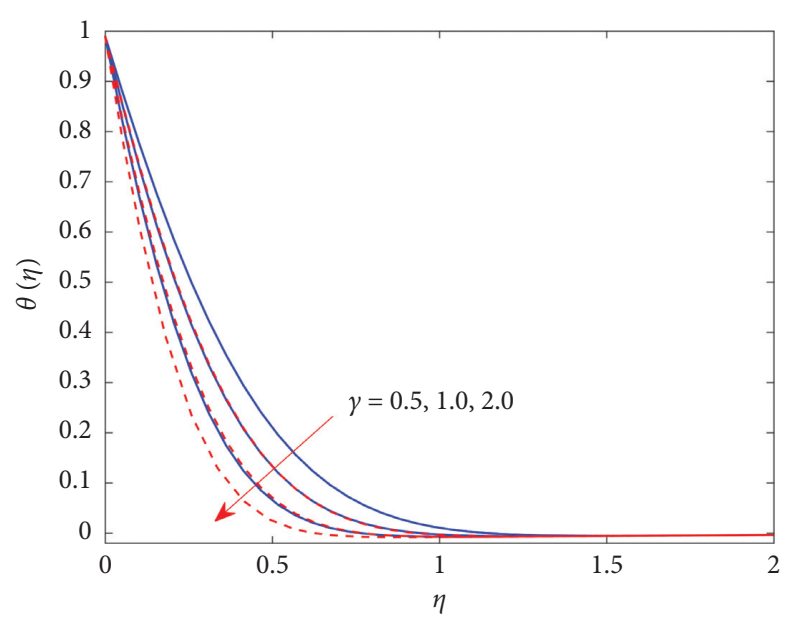

$\begin{array}{ll}\text { - - } & \text { SWCNT - water } \\ \text { — SWCNT - MWCNT/water }\end{array}$

Figure 13: Results of $\gamma$ on $\theta(\eta)$.

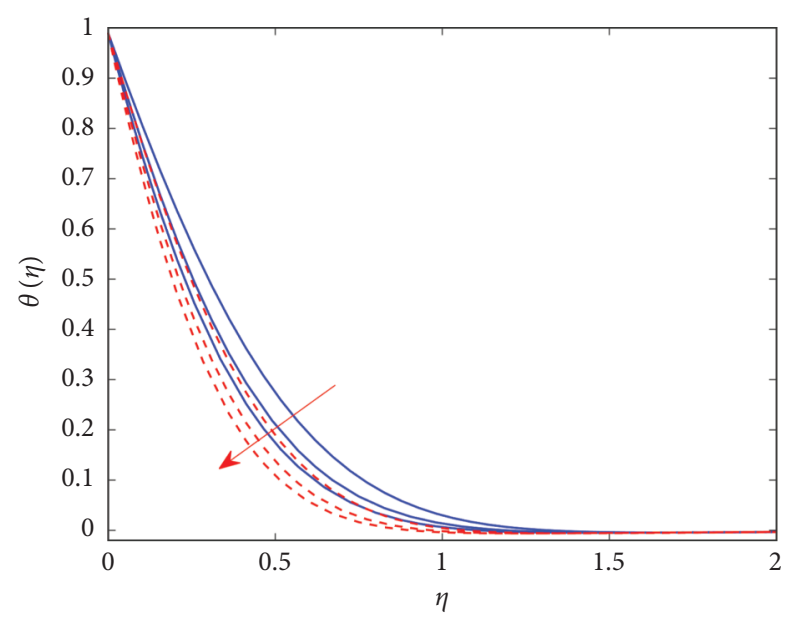

- - - SWCNT-water

SWCNT - MWCNT/water

FIgURE 14: Influence of $\lambda$ on temperature $\theta(\eta)$.

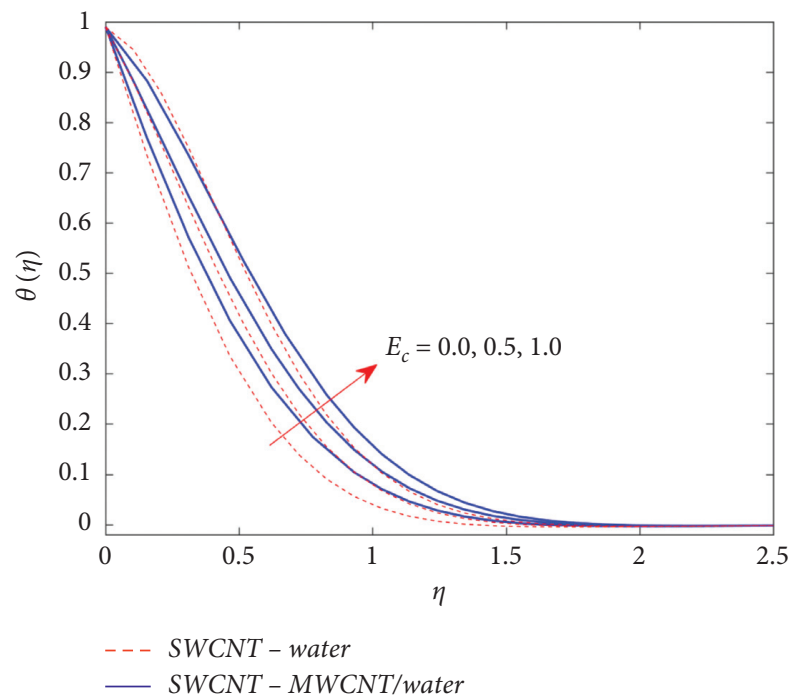

Figure 15: Result of $E_{c}$ on temperature $\theta(\eta)$.

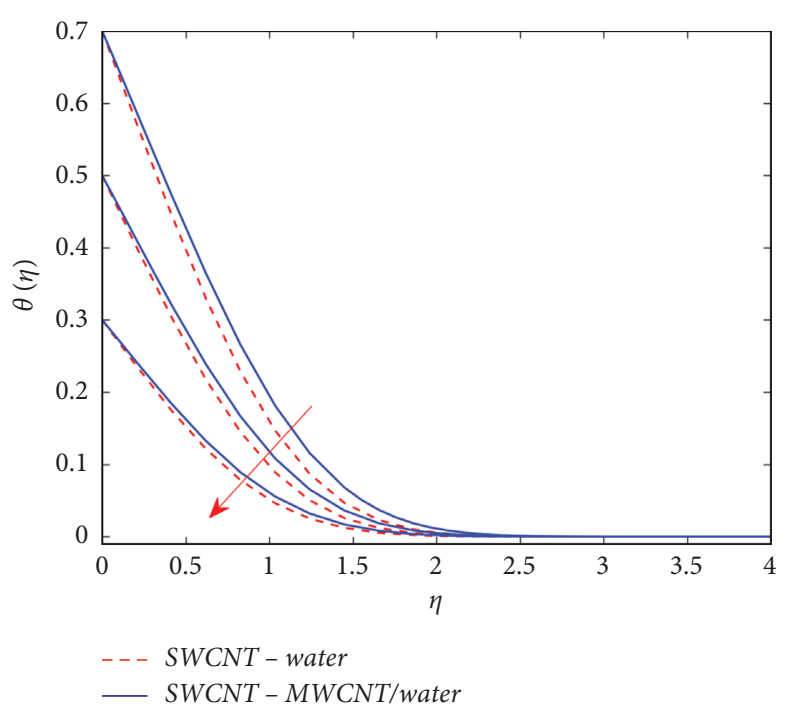

FIgURE 16: Influence of $S_{1}$ on $\theta(\eta)$.

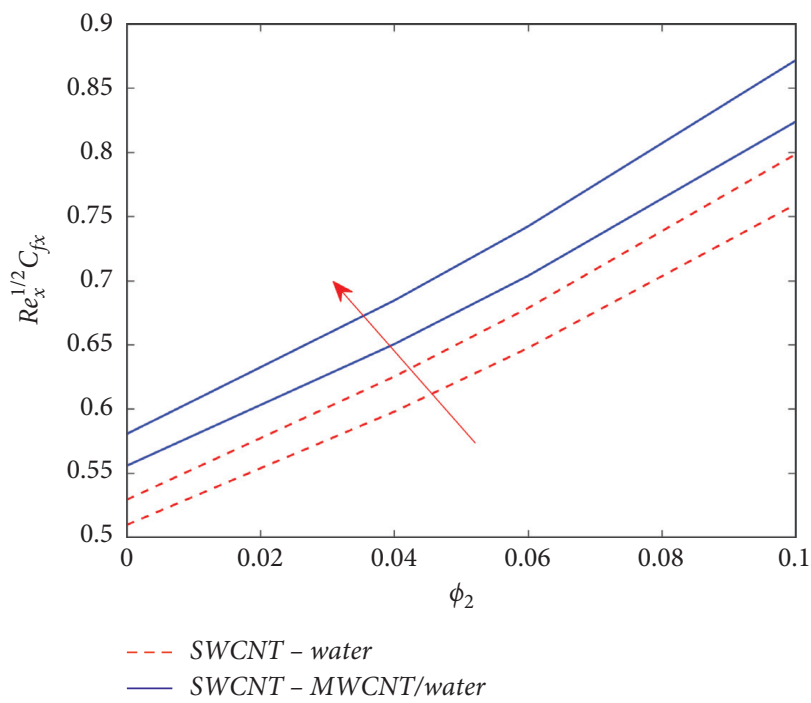

FIgURE 17: $R e_{x}^{(1 / 2)} C_{f x}$ versus $\phi_{2}$ for $\lambda$.

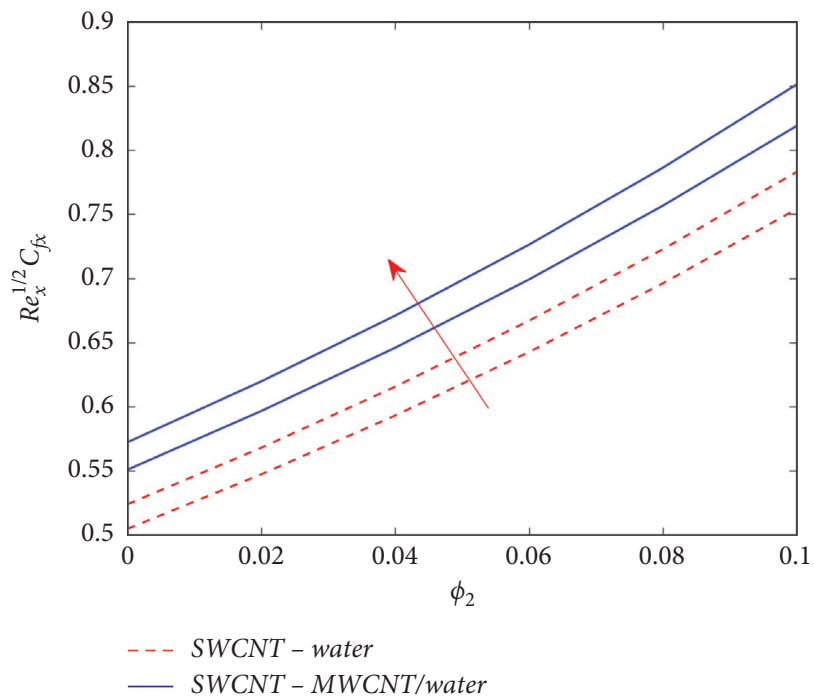

Figure 18: $R e_{x}^{(1 / 2)} C_{f x}$ versus $\phi_{2}$ for $P_{m}$. 


\section{Concluding Remarks}

This article concisely reports on the mixed convective micropolar fluid flow that comprises SWCNT-MWCNT/water hybrid nanofluid towards a partially slipped vertical Riga sheet. The present model is original and new. The problem gains more importance with the effect of thermal stratification, viscous dissipation, and Cattaneo-Christov heat flux. To resolve the transformed ordinary differential equation, the MATLAB bvp4c technique is used to solve the system numerically. The effect of various characteristics on velocity and heat transfer is inspected. Micropolar nanofluids may be used to increase the rate of cooling or heating in all electronic devices. Given below is an important description of such a problem:

(i) Velocity $f^{\prime}(\eta)$ varies inversely with the micropolar parameter $K$ and the nanofluid volume fraction, $\phi_{2}$

(ii) Improving $\theta_{r}$ and $\phi_{2}$ strongly boosts the microrotation profile, but it is a contradictory behavior for K

(iii) Axial friction factor enhances with mixed convection parameter, porosity parameter, and solid volume fraction

(iv) $\theta(\eta)$ is an increasing function of $\phi_{2}$ and $E_{c}$, while decreasing function of $S_{1}, \gamma$, and $\lambda$

(v) Velocity $f^{\prime}(\eta)$ enhances with $s, H a, \theta_{r}$, and $P_{m}$

\section{Nomenclature}

$\begin{array}{ll}(x, y): & \text { Cartesian coordinates } \\ (\bar{u}, \bar{v}): & \text { Velocity components in } x \text { and } y \text { directions } \\ E_{c}: & \text { Eckert number } \\ \kappa: & \text { Vortex viscosity } \\ d: & \text { Electrodes and magnets width } \\ K^{*}: & \text { Porous medium permeability } \\ j: & \text { Microinertia density } \\ g: & \text { Gravitational acceleration } \\ J_{0}: & \text { Density of applied current in the electrodes } \\ C_{p}: & \text { Specific heat }(\mathrm{J} / \text { kg K }) \\ M_{0}: & \text { The permanent magnets' magnetization } \\ \bar{T}: & \text { Temperature of the fluid } \\ T_{\infty}: & \text { Free-stream temperature }(\mathrm{K}) \\ H a: & \text { Modified Hartman number } \\ s: & \text { Slip parameter } \\ K: & \text { Micropolar parameter } \\ l: & \text { Slip length } \\ \bar{u}_{\infty}(x): & \text { Free-stream velocity of the fluid } \\ \bar{N}: & \text { Component of microrotation } \\ f(\eta): & \text { Dimensionless velocity component } \\ g(\eta): & \text { Dimensionless angular velocity component } \\ \operatorname{Pr}: & \text { Prandtl number } \\ G r_{x}: & \text { Grashof number } \\ \operatorname{Re}_{x}: & \text { Local Reynolds number } \\ C_{f}: & \text { Surface drag force. }\end{array}$

\section{Greek symbols}

$\begin{array}{ll}\mu: & \text { Dynamic viscosity } \\ \nu_{f}: & \text { Kinematic viscosity }\end{array}$

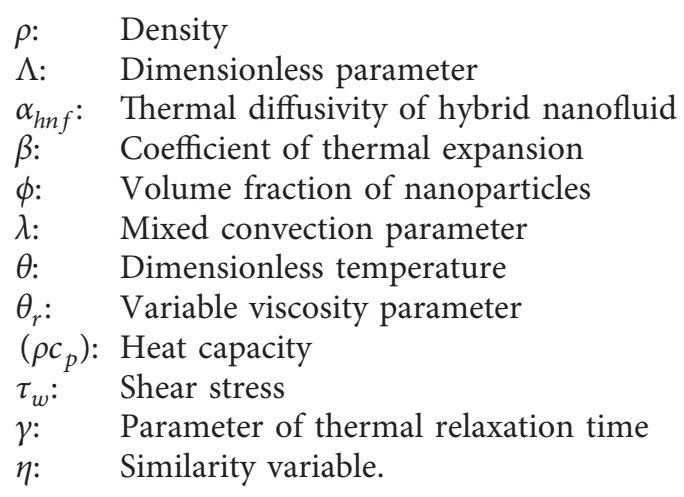

\section{Subscripts}

SWCNT: Single Wall Carbon Nanotube

MWCNT: Multiwall Carbon Nanotube

$f: \quad$ Condition at free stream

$w: \quad$ Wall boundary condition

hnf: $\quad$ Hybrid nanofluid

nf: $\quad$ Nanofluid

$\infty$ : $\quad$ Free-stream condition.

\section{Superscripts}

$\therefore$ Derivative with respect to $\eta$.

\section{Data Availability}

No data were used to support this study.

\section{Conflicts of Interest}

The authors declare that they have no conflicts of interest.

\section{References}

[1] S. U. S. Choi and J. A. Eastman, Enhancing Thermal Conductivity of Fluids with Nanoparticles, Argonne National Lab., Illinois, IL, USA, No. ANL/MSD/CP-84938; CONF-95113529, 1995.

[2] S. Nadeem, S. Ahmad, and N. Muhammad, "Computational study of Falkner-Skan problem for a static and moving wedge," Sensors and Actuators B: Chemical, vol. 263, pp. 69-76, 2018.

[3] L. Dianchen, M. Ramzan, S. Ahmad, J. D. Chung, and U. Farooq, "Upshot of binary chemical reaction and activation energy on carbon nanotubes with Cattaneo-Christov heat flux and buoyancy effects," Physics of Fluids, vol. 29, Article ID 123103, 12 pages, 2017.

[4] E. Rahmat, M. Hassan, and A. Zeeshan, "Study of natural convection MHD nanofluid by means of single and multiwalled carbon nanotubes suspended in a salt-water solution," IEEE Transactions on Nanotechnology, vol. 14, no. 4, pp. 726-734, 2015.

[5] A. Shafiq, S. Nadeem, N. Muhammad, and A. Issakhov, "Radiative SWCNT and MWCNT nanofluid flow of Falkner-Skan problem with double stratification," Physica A: Statistical Mechanics and Its Applications, vol. 547, Article ID 124054, 2020.

[6] M. Sheikholeslami and M. M. Bhatti, "Forced convection of nanofluid in presence of constant magnetic field considering 
shape effects of nanoparticles," International Journal of Heat and Mass Transfer, vol. 111, pp. 1039-1049, 2017.

[7] S. Saleem, M. Qasim, A. Alderremy, and S. Noreen, "Heat transfer enhancement using different shapes of $\mathrm{Cu}$ nanoparticles in the flow of water based nanofluid," Physica Scripta, vol. 95, no. 5, Article ID 055209, 2020.

[8] W. Ibrahim and C. Zemedu, "MHD nonlinear mixed convection flow of micropolar nanofluid over nonisothermal sphere," Mathematical Problems in Engineering, vol. 2020, Article ID 3596368, 20 pages, 2020.

[9] K. Swain and B. Mahanthesh, "Thermal enhancement of radiating magneto-nanoliquid with nanoparticles aggregation and Joule heating: a three-dimensional flow," Arabian Journal for Science and Engineering, pp. 1-9, 2020.

[10] A. Hussain, A. Rehman, S. Nadeem et al., "A combined convection Carreau-Yasuda Nanofluid model over a convective heated surface near a stagnation point: a numerical study," Mathematical Problems in Engineering, vol. 2021, Article ID 6665743, 14 pages, 2021.

[11] N. S. Shashikumar, B. J. Gireesha, B. Mahanthesh, and B. C. Prasannakumara, "Brinkman-Forchheimer flow of SWCNT and MWCNT magneto-nanoliquids in a microchannel with multiple slips and Joule heating aspects," Multidiscipline Modeling in Materials and Structures, vol. 14, no. 4, pp. 769-786, 2018.

[12] B. Mahanthesh and T. V. Joseph, "Dynamics of magneto-nano third-grade fluid with Brownian motion and thermophoresis effects in the pressure type die," Journal of Nanofluids, vol. 8, no. 4, pp. 870-875, 2019.

[13] A. Shafiq and S. Nadeem, "Application of CNT-based micropolar hybrid nanofluid flow in the presence of Newtonian heating," Applied Nanoscience, vol. 10, no. 12, pp. 5265-5277, 2020.

[14] A. Shafiq, S. Nadeem, N. Muhammad, and M. N. Khan, "Cattaneo-Christov heat flux model for stagnation point flow of micropolar nanofluid toward a nonlinear stretching surface with slip effects," Journal of Thermal Analysis and Calorimetry, vol. 143, no. 2, pp. 1187-1199, 2021.

[15] A. Hussain, A. Sobia, S. Lubna, and N. Sohail, "Probe of radiant flow on temperature-dependent viscosity models of differential type MHD fluid," Mathematical Problems in Engineering, vol. 2020, Article ID 2927013, 16 pages, 2020.

[16] T. Muhammad, M. Z. Ullah, H. Waqas, M. Alghamdi, and A. Riaz, "Thermo-bioconvection in stagnation point flow of third-grade nanofluid towards a stretching cylinder involving motile microorganisms," Physica Scripta, vol. 96, no. 3, 2020.

[17] F. Hussain, A. Hussain, and S. Nadeem, "Thermophoresis and Brownian model of pseudo-plastic nanofluid flow over a vertical slender cylinder," Mathematical Problems in Engineering, vol. 2020, Article ID 8428762, 10 pages, 2020.

[18] B. Mahanthesh, B. J. Gireesha, and R. S. R. Gorla, "Nanoparticles effect on 3D flow, heat and mass transfer of nanofluid with nonlinear radiation, thermal-diffusion and diffusionthermo effects," Journal of Nanofluids, vol. 5, no. 5, pp. 669-678, 2016.

[19] B. Mahanthesh, B. J. Gireesha, S. A. Shehzad, N. Ibrar, and K. Thriveni, "Analysis of a magnetic field and Hall effects in nanoliquid flow under insertion of dust particles," Heat Transfer, vol. 49, no. 3, pp. 1632-1648, 2020.

[20] S. Nadeem, S. Ahmad, and N. Muhammad, "Analysis of ferrite nanoparticles in liquid,” Pramana, vol. 94, pp. 1-9, 2020.

[21] H. Mohsan, M. Marin, R. Ellahi, and S. Z. Alamri, "Exploration of convective heat transfer and flow characteristics synthesis by $\mathrm{Cu}-\mathrm{Ag} /$ water hybrid-nanofluids," Heat Transfer Research, vol. 49, p. 18, 2018.

[22] A. Shafee, M. Sheikholeslami, M. Jafaryar, and H. Babazadeh, "Irreversibility of hybrid nanoparticles within a pipe fitted with turbulator," Journal of Thermal Analysis and Calorimetry, vol. 143, no. 1, pp. 715-723, 2021.

[23] S. Ahmad, S. Nadeem, and N. Ullah, "Entropy generation and temperature-dependent viscosity in the study of SWCNT-MWCNT hybrid nanofluid," Applied Nanoscience, vol. 10, no. 12, pp. 5107-5119, 2020.

[24] I. M. Alarifi, A. B. Alkouh, V. Ali, H. M. Nguyen, and A. Asadi, "On the rheological properties of MWCNT-TiO2/ oil hybrid nanofluid: an experimental investigation on the effects of shear rate, temperature, and solid concentration of nanoparticles," Powder Technology, vol. 355, pp. 157-162, 2019.

[25] S. A. M. Mehryan, E. Izadpanahi, M. Ghalambaz, and A. J. Chamkha, "Mixed convection flow caused by an oscillating cylinder in a square cavity filled with $\mathrm{Cu}-\mathrm{Al} 2 \mathrm{O} 3 /$ water hybrid nanofluid," Journal of Thermal Analysis and Calorimetry, vol. 137, no. 3, pp. 965-982, 2019.

[26] L. S. Sundar, M. K. Singh, and A. C. M. Sousa, "Enhanced heat transfer and friction factor of MWCNT-Fe3O4/water hybrid nanofluids," International Communications in Heat and Mass Transfer, vol. 52, pp. 73-83, 2014.

[27] M. Baghbanzadeh, A. Rashidi, A. H. Soleimanisalim, and D. Rashtchian, "Investigating the rheological properties of nanofluids of water/hybrid nanostructure of spherical silica/ MWCNT," Thermochimica Acta, vol. 578, pp. 53-58, 2014.

[28] J. Mackolil and B. Mahanthesh, "Exact and statistical computations of radiated flow of nano and Casson fluids under heat and mass flux conditions," Journal of Computational Design and Engineering, vol. 6, no. 4, pp. 593-605, 2019.

[29] Z. Hussain and T. Muhammad, "Simultaneous influence of Hall and wall characteristics in peristaltic convective carbonwater flow subject to soret and dufour effects," Arabian Journal for Science and Engineering, vol. 46, no. 3, pp. 2033-2046, 2021.

[30] S. Nadeem, A. U. Khan, and S. T. Hussain, "Model based study of SWCNT and MWCNT thermal conductivities effect on the heat transfer due to the oscillating wall conditions," International Journal of Hydrogen Energy, vol. 42, no. 48, pp. 28945-28957, 2017.

[31] B. Mahanthesh, S. A. Shehzad, T. Ambreen, and S. U. Khan, "Significance of Joule heating and viscous heating on heat transport of MoS 2-Ag hybrid nanofluid past an isothermal wedge," Journal of Thermal Analysis and Calorimetry, pp. 1-9, 2020.

[32] A. Afshari, M. Akbari, D. Toghraie, and M. F. Yazdi, "Experimental investigation of rheological behavior of the hybrid nanofluid of MWCNT-alumina/water (80\%)-ethylene-glycol (20\%)," Journal of Thermal Analysis and Calorimetry, vol. 132, no. 2, pp. 1001-1015, 2018.

[33] J. Mackolil and B. Mahanthesh, "Sensitivity analysis of Marangoni convection in TiO2-EG nanoliquid with nanoparticle aggregation and temperature-dependent surface tension," Journal of Thermal Analysis and Calorimetry, vol. 143, no. 3, pp. 2085-2098, 2021.

[34] A. Gailitis, "On the possibility to reduce the hydrodynamic drag of a plate in an electrolyte," Appl. Magnetohydrodynamics, Rep. Inst. Phys. Riga., vol. 13, pp. 143-146, 1961.

[35] A. Zaib, U. Khan, I. Khan, A. H. Seikh, and E. S. M. Sherif, "Entropy generation and dual solutions in mixed convection 
stagnation point flow of micropolar Ti6Al4V nanoparticle along a Riga surface," Processes, vol. 8, no. 1, p. 14, 2020.

[36] T. Abbas, M. Ayub, M. Bhatti, M. Rashidi, and M. Ali, "Entropy generation on nanofluid flow through a horizontal Riga plate," Entropy, vol. 18, no. 6, p. 223, 2016.

[37] A. Ahmad, S. Asghar, and S. Afzal, "Flow of nanofluid past a Riga plate," Journal of Magnetism and Magnetic Materials, vol. 402 , pp. 44-48, 2016.

[38] E. Magyari and A. Pantokratoras, "Aiding and opposing mixed convection flows over the Riga-plate," Communications in Nonlinear Science and Numerical Simulation, vol. 16, no. 8, pp. 3158-3167, 2011.

[39] K. Anantha Kumar, V. Sugunamma, and N. Sandeep, "Influence of viscous dissipation on MHD flow of micropolar fluid over a slendering stretching surface with modified heat flux model," Journal of Thermal Analysis and Calorimetry, vol. 139, no. 6, pp. 3661-3674, 2020.

[40] K. A. Kumar, V. Sugunamma, N. Sandeep, and M. T. Mustafa, "Simultaneous solutions for first order and second order slips on micropolar fluid flow across a convective surface in the presence of Lorentz force and variable heat source/sink," Scientific Reports, vol. 9, no. 1, pp. 14706-14714, 2019.

[41] K. A. Kumar, N. Sandeep, and V. Sugunamma, "Numerical investigation of MHD nonlinear radiative oblique flow of micropolar liquid past a stretching sheet with porous medium," Special Topics and Reviews in Porous Media: An International Journal, vol. 10, 6 pages, 2019.

[42] S. Nadeem, S. Ahmad, and M. N. Khan, "Mixed convection flow of hybrid nanoparticle along a Riga surface with Thomson and Troian slip condition," Journal of Thermal Analysis and Calorimetry, vol. 143, no. 3, pp. 2099-2109, 2020.

[43] F. Aman, A. Ishak, and I. Pop, "Mixed convection boundary layer flow near stagnation-point on vertical surface with slip," Applied Mathematics and Mechanics, vol. 32, no. 12, pp. 1599-1606, 2011.

[44] U. Khan, S. Ahmad, A. Hayyat, I. Khan, K. S. Nisar, and D. Baleanu, "On the Cattaneo-Christov heat flux model and OHAM analysis for three different types of nanofluids," Applied Sciences, vol. 10, no. 3, p. 886, 2020.

[45] K. S. Nisar, U. Khan, A. Zaib, I. Khan, and A. Morsy, "A novel study of radiative flow involving micropolar nanoliquid from a shrinking/stretching curved surface including blood gold nanoparticles," The European Physical Journal Plus, vol. 135, no. 10, pp. 1-19, 2020. 